\title{
LINGUAGEM EM SOCIEDADE: INTERAÇÕES, SENTIDOS E EMANCIPAÇÃO
}

\section{LANGUAGE IN SOCIETY: INTERACTIONS, MEANINGS AND EMANCIPATION}

\author{
Rosemary do Nascimento Silveira" \\ Letícia Adriana Pires Ferreira dos Santos ${ }^{* * *}$ \\ Claudiana Nogueira de Alencar ${ }^{* * * *}$
}

\begin{abstract}
Resumo: $O$ texto apresenta o conceito de linguagem como constructo em permanente movimento, que inclui as dimensões intersubjetivas, sociais, ideológicas e políticas. Objetiva-se refletir sobre concepções de Linguagem, em uma perspectiva crítica, destacando sua constituição sócio-cultural e ideológica. Para tal, realiza-se uma discussão teórica, com ênfase em estudiosos da Linguagem como Rajagopalan (2010, 2014a, 2014b), Fabrício (2006), entre outros que a compreendem para além de uma concepção linguística formalista, concebendo-a em sua constituição dialética com o mundo. Dado o caráter interdisciplinar do tema, realiza-se breve incursão na Psicanálise, a fim de se enfatizar uma compreensão da linguagem que considere o funcionamento da consciência e seu entrelaçamento com a dimensão do inconsciente. Como resultado, evidencia-se a inseparável relação linguagem-estrutura social. Linguagem que cria realidades, em uma sociedade marcada por discursos que legitimam a opressão. Entretanto, reitera-se a possibilidade do sujeito no discursoato, que pode se mover contra o subjugo, que não é condição natural ou imutável.
\end{abstract}

Palavras-chave: Discurso; ideologia; sujeito.

\begin{abstract}
The text presents language as a construct in permanent movement, which includes the intersubjective, social, ideological and political dimensions. The objective is to reflect on conceptions of Language, in a critical perspective, highlighting its
\end{abstract}

\footnotetext{
"Doutoranda do curso de Linguística Aplicada da Universidade Estadual do Ceará (UECE). Mestre em Psicologia pela Universidade Federal do Ceará (UFC). Graduada em Psicologia pela UFC. Professora do Curso de Psicologia da Universidade Estadual do Ceará (UECE). Psicanalista. E-mail: rosemary. silveira@uece.br.

** Pós-doutorado, Doutorado e Mestrado em Linguística pela Universidade Federal do Ceará (UFC). Graduada em Letras pela UFC. Professora do Programa de Pós-Graduação em Linguística Aplicada da Universidade Estadual do Ceará (UECE).E-mail: letícia.santos@uece.br.

**** Pós-doutorado em Semântica/pragmática pela Universidade Estadual de Campinas (Unicamp). Mestrado e doutorado em Linguística pela Unicamp. Graduada em Letras pela Universidade Estadual do Ceará (UECE). Professora do Programa de Pós-Graduação em Linguística Aplicada da UECE. E-mail: claudiana.alencar@uece.br.
} 
socio-cultural and ideological constitution. It is proposed a theoretical discussion with an emphasis on authors like Rajagopalan (2010, 2014a, 2014b), Fabrício (2006), among others who understand it beyond a formalist linguistic conception, conceiving it in its dialectical constitution. Due to the interdisciplinary nature of the theme, a brief incursion into Psychoanalysis is conducted, which brings an understanding of the language that considers the functioning of consciousness intertwined with the unconscious. As a result, the inseparable relationship between language and social structure is evident. Language creates realities, in a society permeated by discourses that legitimize oppression. However, the possibility of a subject in the speech-act is reiterated, who can move against subjugation, which is not a natural or immutable condition.

Keywords: Discourse; ideology; subject.

\section{INTRODUÇÃo}

Este texto tem sua origem a partir de uma disciplina de Análise de Discurso Crítica, de um curso de doutorado em Linguística Aplicada, em uma universidade pública, durante o segundo semestre do ano de 2018, momento em que vivíamos no Brasil a efervescência de um período eleitoral, com tudo o que isso propiciava de dúvidas, temeridades e esperança. Durante as aulas, em meio às leituras, aos enredos particulares que cada um contava e ao entrelaçamento dos discursos em suas aproximações, distanciamentos e contradições, a experiência nos conduzia a uma ideia sobre a linguagem, em suas múltiplas possibilidades (texto escrito, lido, fala, gestos, silêncios, imagem etc.), como conceito complexo e que, impreterivelmente, suscita discussões no campo da política, da ética e das relações humanas.

Com este escrito, pretendemos realizar uma explanação sobre concepções de linguagem e os desdobramentos que ideias, conceitos e percepções acerca de um fenômeno podem trazer às sociedades e à vida dos sujeitos, aos seus modos de existência e de relação com o outro. Um dos elementos que destacamos é a necessidade de enxergarmos a linguagem (seu uso) também como um veículo de segregação, de definição de lugares sociais e de posições de sujeitos que acabam tendo, ideologicamente, suas condições culturais, econômicas e subjetivas concebidas como algo natural, como uma espécie de herança, cuja origem supostamente não precisaria ser buscada.

Pinto (2014) compreende discursos (hegemônicos) em sua força de permanência, mas também de transitoriedade, em meio a uma existência complexa e contraditória. Traz uma concepção de discurso em seu aspecto performativo, entendendo que não apenas descrevemos aquilo (eventos, fenômenos, conceitos) sobre o qual falamos e, sim, construímos uma realidade. Quando enunciamos algo, interferimos no mundo social ativamente. Uma narrativa, elogiosa ou depreciativa sobre sujeitos, povos ou nações, assim como determinadas descrições, pode definir vidas, indivíduos, grupos e lugares sociais. A linguagem, embora atue no campo da 
impermanência, como elemento social que é, e não seja um mero instrumento, mas algo que só existe na ação, numa práxis, pode produzir efeitos positivos ou nefastos à vida de muitos sujeitos, de forma duradoura ou provisória.

Essa discussão nos leva a uma preocupação urgente com o lugar ocupado pelos discursos na sociedade atual, marcada intensamente pelo uso e velocidade do fluxo de informação, pela utilização política e insidiosa de narrativas, pela tecnologia da imagem, no que ela tem de agregador, necessário e, também, de falseador e destrutivo. Ratificamos uma postura crítica frente à linguagem, situando-a histórica e socialmente, e reconhecemos o lugar central que ela ocupa nos intercâmbios humanos, tanto em seu potencial emancipador, quanto em seu poderio de violência e de opressão, que opera, muitas vezes, de forma explícita, mas também de modo invisível ou "disfarçado".

O artigo está organizado em três seções, incluindo essa apresentação (seção 1), a seção 2 , que trata da relação entre linguagem e sua significação, com ênfase numa perspectiva social e política, e as considerações finais (seção 3). No que tange à seção 2, apresentamos duas subseções. Na subseção 2.1, realizamos uma discussão crítica sobre o advento da ciência Moderna e seu paradigma objetivista, e a influência desse modelo de cientificidade para os diferentes campos do conhecimento, dentre os quais os estudos da linguagem.

Na subseção 2.2, apresentamos uma reflexão sobre concepções de linguagem, desde quando concebida sob uma perspectiva individualizante e a-histórica, ao estudo de autores que a compreendem como um fenômeno complexo, cuja constituição deve ser pensada na relação dialética entre sujeito e sociedade. Nessa seção, fazemos breve menção a uma discussão que autores como Rajagopalan (2014b), Pinto (2014) e Blommaert (2014) realizam sobre a concepção de língua e os seus desdobramentos políticos e ideológicos nas práticas de linguagem (foco do presente artigo) efetivadas no cotidiano. Essa discussão nos alerta para pensarmos a relação entre a visão que se tem sobre um conceito, no caso o de língua, seus significados sociais, o uso da linguagem advindo dessa concepção, e os efeitos produzidos na vida dos sujeitos. $\mathrm{Na}$ seção final, enfatizamos a importância de uma compreensão da linguagem como ato que, longe de ser concebido como objeto isolado, abstraído de seu envoltório social, é posicionado como um fenômeno complexo e que deve ser reconhecido em sua constituição ideológica, intersubjetiva e histórico-política.

\section{LINGUAGEM E SIGNIFICAÇÃO: CONSTITUIÇÃo SOCIAL E POLÍTICA}

\section{CONHECIMENTO, PRÁtiCAS DISCURSIVAS E PODER}

Uma discussão sobre a linguagem nos convida, inicialmente, a um debate sobre o conhecimento, seja o dito do senso comum ou aqueles definidos como científicos, ambos muitas 
vezes legitimados como verdadeiros e inquestionáveis. O tema nos conduz à inextricável relação entre práticas discursivas, saberes, o mundo que temos e aquele com o qual sonhamos.

Discorrer sobre a linguagem, em especial referenciando uma disciplina de Análise de Discurso Crítica, nos faz pensar sobre a responsabilidade ética que acompanha um dizer sobre o outro. Também, conduz-nos a retornar há alguns séculos, mais precisamente ao XVII, quando os sujeitos começam a ser definidos como objetos de investigação, pelo que se chamou ciência Moderna.

Esse padrão de ciência é influenciado em seus primórdios pelas ideias de René Descartes (1596-1650) e pelo empirismo de Francis Bacon (1561-1626), que tinham posicionamentos filosóficos antagônicos, mas com aproximações no plano do interesse utilitário nas relações sujeito-mundo. E é nesse contexto histórico que surge uma concepção de conhecimento marcada pelo adaptacionismo e o controle, e atravessa as obras de diversos autores, dentre os quais os empiristas ingleses John Locke (1632-1704), David Hume (1711-1776) e o positivista Augusto Comte (FIGUEIREDO, 2000).

Desse modelo de cientificidade, surge um método de investigação pautado numa razão instrumental, que vai se desenvolvendo ao longo dos séculos seguintes, e ainda com ecos na atualidade, que, em nome de um "estatuto de verdade", almeja mapear os corpos, descrever os comportamentos humanos e cada ato manifestado, por mais oscilante, como se fosse uma expressão objetiva e de possível controle.

Rajagopalan (2014a), ao discutir a ideia de rigor científico, comenta sobre um tipo de endeusamento da razão em detrimento de outras dimensões da mente humana, e faz uma crítica à crença de que uma área, a Pragmática, por exemplo, por não possuir rigor científico com base na matemática (e na lógica), supostamente não teria valor de investigação. Nesse caso, ocorre um reducionismo na análise de um fenômeno, que fica atrelado a uma concepção de ciência com base na racionalidade e na quantificação para que tenha legitimidade.

A busca de um modo "correto" do uso da racionalidade para se apreender o fenômeno humano, sem interferência das crenças, sentimentos e intuições, almejado por Descartes, fracassa, exatamente, por desconhecer a marca indelével dos sujeitos (do pesquisador e de seu "objeto"), que é a impossibilidade da retirada da subjetividade. Nessa direção, esse modelo de ciência tenta se legitimar pela negação de um sujeito.

Rajagopalan (2010), em texto que discute a concepção de língua numa perspectiva individualista e racionalista de análise, enfatiza que muito do campo da pragmática principiante e da linguística tradicional, como um todo, realizava uma cisão entre língua e sua constituição social, como se a mente fosse uma espécie de faculdade a parte, uma entidade isolada de seu indissociável envoltório sociocultural. $\mathrm{O}$ autor ressalta que:

Não é de surpreender, portanto, que na medida em que a faculdade linguística humana era vista como uma propriedade da mente racional 
do homem, a própria linguagem era considerada primariamente como pertencente ao falante-ouvinte e apenas secundariamente à sociedade, por derivação (RAJAGOPALAN, 2010, p. 37).

Na passagem do século XIX para o século XX, o psicanalista vienense Sigmund Freud (1856-1939) põe em questão a ciência (psiquiátrica) da época, produzindo uma ruptura com o modelo biologicista, racionalista e descritivo de estudo dos fenômenos psíquicos. Em uma conferência para médicos, datada de 1916, enfatiza que a vida mental caracterizada pelo sentir, o pensar e o querer, não podia ser concebida a partir da mera descrição de fenômenos observáveis, numa perspectiva mecanicista de conhecimento. Para ele, a vida psíquica é marcada também por processos inconscientes, em grande proporção, tendo como instrumento central de compreensão do humano a linguagem, aqui pensada em sua dimensão de palavra e ato (ação, sintoma).

Freud (1986a) estava atento ao discurso de um sujeito (dividido), cuja linguagem para o autor não era óbvia. O discurso "apresenta" a história do sujeito de modo indireto, por meio de manifestações diversas, que não poderiam ser alcançadas pela linearidade da ciência positivista, a qual não compreende que, na palavra-ato latente, e não apenas no discurso manifesto, também reside a "verdade" de um sujeito. Freud (1986a) ratifica o valor da linguagem, nos intercâmbios entre os sujeitos, assim como no trabalho de análise:

Os desinformados [...], que se impressionam apenas com coisas visíveis e tangíveis [...] jamais deixam de expressar suas dúvidas quanto a saber se 'algo pode ser feito pela doença, que não seja simplesmente falar' [...] Por meio da palavra uma pessoa pode tornar outra jubilosamente feliz ou levá-la ao desespero, por palavras o professor veicula seu conhecimento aos alunos, por palavras o orador conquista seus ouvintes para si e influencia o julgamento e as decisões dele. Palavras suscitam afetos e são, de modo geral, o meio de mútua influência entre os homens (FREUD, 1986a, p. 29-30).

O ser humano, mediado pela linguagem, dirige-se e apreende o mundo, espaço constituído por uma complexa realidade simbólica, produzindo sentidos ativamente, e constituindo suas fantasias, sonhos, concepções sobre si e sobre o mundo. Com o seu dizer/fazer, reconstrói significados, produzindo novos sentidos, o que permite à linguagem o lugar de agente de transformação. Para Freud (1986a), a linguagem aparece como um elemento essencial de expressão (e não apenas) que revela e oculta, mostra e disfarça, não somente por meio da palavra, mas de atos, do silêncio e, até, de processos de adoecimentos psíquicos. Nessa perspectiva, a psicanálise freudiana demarca a complexidade contida em um discurso e a ideia de que os sentidos da linguagem não são sempre captáveis diretamente, mas atravessados também por manifestações do inconsciente. Enfatiza, nesse sentido, que a expressão linguística precisa ser compreendida a partir da marca singular de quem a enuncia, de sua história (inter) subjetiva. 
Quando entrelaçamos a discussão sobre linguagem ao conhecimento científico, estamos atentas ao reconhecimento da ciência para a sociedade contemporânea, o que abrange ganhos nos diversos setores da vida, seja no âmbito da saúde, da educação, das indústrias, das tecnologias etc. Contudo, essa percepção não nos isenta de demarcarmos que há contradições constitutivas desse projeto de cientificidade, e que estão na raiz de diversos campos do conhecimento, entre eles os estudos sobre a linguagem. Afinal, o saber é uma formação discursiva e implica concepções acerca dos fenômenos, das sociedades, dos indivíduos e grupos, e, consequentemente, implica estruturas de poder.

Foucault (2003) faz uma interessante observação em seu livro Microfísica do Poder, quando sugere que estruturas de poder não são apenas fomentadas pela repressão, pela imposição, pelo não. E sim, há produção de "coisas", indução ao prazer, formação de saber e produção de discurso. Acentua que existem "verdades" sendo produzidas em cada sociedade, ou seja, tipos de discursos que se acolhe e se faz funcionar como verdadeiros. Nessa direção, o poder, "longe de impedir o saber, o produz" (Foucault, 2003, p. 148).

A esse respeito, Blommaert (2008) considera que as estruturas de poder atingem determinadas complexidades que não são necessariamente "mostradas" nos discursos. Segundo o autor, as abordagens críticas do discurso:

[...] também devem se preocupar com o poder invisível, hegemônico, normalizado - o poder 'capilar' de Foucault e a burguesia capitalista invisível de Barthes - na linguagem e não pela linguagem. Como todos sabemos, a linguagem é ela mesma um objeto de desigualdade e hegemonia" (BLOMMAERT, 2008, p. 114).

Com a discussão acerca da produção do conhecimento, dos discursos que o sustentam, e dos aspectos político-ideológicos implicados, evidenciamos o cuidado com os modos de atuação de pesquisadores/analistas de discursos frente aos seus "objetos", pois não podemos produzir generalizações de métodos e análises sem levar em consideração a complexidade dos fenômenos e dos sujeitos investigados. Seguimos uma preocupação, que consideramos bem atual, de Japiassu (1982) quando se refere à ciência calcada numa perspectiva positivista, "porque tudo indica que, em nossos dias, sua pretensa cientificidade é proporcional a sua desumanidade; quanto mais "científicas" se tornam, menos humanas se revelam [...]" (Japiassu, 1982, p. 9).

Acreditamos ser grande o risco para a ciência, em sua busca por legitimidade, apostar na certeza inquestionável e isenta de imprevistos, em especial quando se trata da investigação acerca de um sujeito falante. Utilizamos a expressão "falante" para designarmos algo que não se esgota na oralidade. Tratamos da linguagem em seu caráter semiótico, polissêmico, multideterminado e que comporta também um não-saber, uma inexatidão e a imprevisibilidade no discurso. 


\section{CONCEPÇÕES DE LINGUAGEM: DA ÊNFASE NA FORMA À IDEIA DE UM DISCURSO-ATO}

No campo dos estudos Linguísticos, temos um longo percurso desde o linguista suíço Ferdinand Saussure (1857-1913). De acordo com Mussalin (2012), Saussure concebe o funcionamento da língua como autônomo em relação ao mundo externo. Nesse sentido, possui um mecanismo cujas regularidades poderiam ser estudadas pela ciência sem, necessariamente, se realizar uma conexão direta com as estruturas político-econômicas e culturais da sociedade. Embora Saussure conceba a fala, ao contrário da língua, como elemento que varia em decorrência dos usos realizados pelos falantes, sua visão dicotômica de linguagem o impede de avançar no reconhecimento da trama ideológica (histórica) que está na base das existências desses falantes e de suas instituições.

Diante dessa perspectiva, Mussalin (2012) salienta que a linguística, cujo objeto é a língua como sistema, não focaria a significação no que ela possui de fundamental, que é sua constituição simbólica. Para a autora, a significação só pode ser apreendida na ordem do discurso e das posições ocupadas pelo sujeito falante, sendo nas condições sociais e históricas de produção de um discurso que percebemos suas redes de sentidos.

A ideia de uma língua como estruturalmente distinta da fala, sendo a primeira uma regra que está fora do contexto do falante individual, ou seja, concebida como independente das intenções dos sujeitos, traz uma grande complicação para entendermos a linguagem em sua complexidade, conforme enfatiza Leezenberg (2014). Nessa perspectiva, a língua é caracterizada como um conjunto de regras que os sujeitos compartilham com o intuito de se beneficiar individualmente e na sua convivência em sociedade. Para o autor,

a ideologia da linguagem como contrato social não é simplesmente uma variação do individualismo metodológico. Mais do que isso, tal ideologia implica, crucialmente, uma visão consensual da comunicação linguística voltada a reproduzir a integração e a estabilidade social (LEEZENBERG, 2014, p. 47).

Essa visão possui implicações muito sérias na existência concreta de uma comunidade, posto que concebe ideologicamente os intercâmbios linguísticos como reprodutores de uma suposta estabilidade social. Caso aceitássemos esse postulado, acreditaríamos estar diante de sujeitos passivos, submetidos ao código, ao pré-estabelecido, e não de atores sociais e transformadores da estrutura social da qual fazem parte.

Como Blommaert (2014), são muitos os pesquisadores atuais que têm ampliado a compreensão da relação inseparável entre linguagem e práticas sociais/discursivas, observando-a "em uso, imbricada em ampla amalgamação de fatores contextuais" (FABRÍCIO, 2006, p. 49). Em outras palavras, caminhamos para a compreensão de que estudar o discurso é estudar sociedade e cultura, que o constitui e que é por ele constituída. Cabe-nos frisar, que, embora com os avanços efetivados nos estudos da linguagem, subsistem trabalhos, como a obra de 
Davis (1991 apud RAJAGOPALAN, 2010), que focam numa visão tradicional, concebendo-a como objeto em si, isolada, não sendo considerada sob uma perspectiva histórico-social.

Interpretações acerca dos eventos humanos, dos discursos e suas histórias estão na esfera da linguagem e do sentido, não havendo "significados que independam de um contexto de uso" (SILVA; ALENCAR, 2014, p. 259). Não são apenas hermenêuticas diante de campos particulares ou de um dito imediato e isolado de uma existência social. O que ouvimos/lemos carrega histórias que abrangem e transcendem a própria imediatez dos discursos, com seus desejos, ideologias e posições políticas. Na citação a seguir, Fabrício (2006) relaciona o sentido com o modo como se emprega a linguagem na vida cotidiana, nos indicando que não pode haver uma compreensão única para palavras ou outras formas de expressão, posto que é no contexto sociocultural, no intercâmbio com o outro que a linguagem alcança significação.

O sentido, assim, não é algo que acompanha a palavra, pois uma palavra só se torna significativa no seu uso em determinadas circunstâncias e contextos de comunicação. Isso quer dizer que a significação não é algo anterior às práticas discursivas vigentes em uma comunidade das quais aprendemos a participar. Haveria, então, vínculo indissociável entre linguagem, produção de sentidos, contexto, comportamento social e atividades humanas, o que aponta o entrelaçamento entre cultura, práticas discursivas, conhecimento e visão de mundo. (FABRÍCIO, 2006, p. 57).

Nos estudos de Fairclough (2008), encontramos uma concepção dialética do discurso como fenômeno que se constitui nas práticas de vida em sociedade. Nesse sentido, ele é determinado por uma estrutura (social), que é constituída a partir de intercâmbios linguísticos. O discurso designa uma prática social que implica processos de significação do mundo e não apenas a expressão de sua representação. Nessa perspectiva, temos um sujeito do discurso que é ativo em sua realidade, sendo agente na construção das identidades sociais, das relações entre os sujeitos e de sistemas de conhecimentos acerca do mundo. São esses os efeitos que o discurso produz, que correspondem ao que Fairclough (2008) denominou de funções da linguagem.

Devemos, por conseguinte, também reconhecer a dimensão político-ideológica em nós, assumindo a autoria do que escolhemos, de como compreendemos os discursos e do tipo de análise e intervenção que pretendemos. Não é possível analisar, interpretar ou mesmo descrever (textos) sem que sentimentos, desejo, motivos e interesses atravessem esses atos. Reconhecer isso é um passo essencial para a criação de um posicionamento crítico e ético acerca do trabalho com a linguagem.

No que tange ao aspecto político-ideológico que acompanha a compreensão das práticas de linguagem, em diferentes contextos institucionais, seja de ensino ou outros ambientes profissionais, Rajagopalan (2014b) realiza uma importante observação acerca da distância do 
ensino de língua na escola e da língua que falamos cotidianamente, assim como sobre o uso de expressões (jargões) peculiares a uma determinada profissão. Nesse estudo, aponta para o caráter de inacessibilidade linguística que se apresenta em determinados contextos e nos alerta para o hermetismo linguístico como a expressão de um elitismo, algo que não ocorre aleatoriamente, mas como um meio de não permitir um acesso coletivo a determinados saberes.

Por mais que consideremos a aprendizagem formal da língua como necessária à inserção profissional, por exemplo, não podemos ignorar que eleger como modelo padrão a "norma culta" não se deu ao acaso na história, mas em nome de uma divisão entre os saberes e, principalmente, de uma hierarquia entre sujeitos e sociedades (RAJAGOPALAN, 2014b). Designar como "língua oficial" um modo de expressão a ser estudado/apreendido, em oposição a um modelo rotulado como "incorreto", "inadequado", "não culto", é uma forma de discriminar as variedades linguísticas existentes em nossa sociedade e de negar que línguas são construções histórico-sociais, não devendo existir a ideia de um modelo "original" ou "autêntico" a ser estabelecido.

Salientamos que um modo de conceber a língua é eminentemente político, pois traz não apenas uma descrição sobre um fenômeno, mas uma maneira de pensar e de agir sobre os sujeitos. Nesse sentido é que entendemos que concepções sobre língua podem funcionar como instrumentos de discriminação, de desrespeito à diferença, materializando-se por meio de práticas de linguagem preconceituosas e segregadoras, em especial, nos espaços escolares.

Blommaert (2014) também apresenta uma discussão acerca das ideologias linguísticas, as quais se referem a ideias, concepções sobre linguagem e comunicação humana. Segundo o autor, a língua não pode ser reduzida a uma análise formal (artefatos gráficos e textuais, por exemplo) como se fossem separados de uma estrutura sócio-cultural e de suas complexas organizações de poder. Salienta a gravidade que ocorre quando formas e regras linguísticas são concebidas como o modelo ideal, um tipo de "língua padrão" a ser adotado, rotulando-se determinadas formas de linguagem como "incorretas", "inadequadas", "com sotaque", "não cultas”. Para o autor, as ideologias são, na verdade, práticas. Nessa direção, elas criam realidades, passando a construir uma associação língua-nível de escolaridade, status, classe social; o que implica segregação, posicionamento de lugares sociais específicos e, por conseguinte, de relações de poder e, por vezes, de subjugo.

Pinto (2014) evidencia existir uma concepção de língua no Brasil que privilegia a forma escrita, o que acaba por referenciar a escolarização ou "erudição" intelectual como modelo de civilização e racionalidade, em oposição à língua falada, percebida como processo natural. Une-se a essa ideia uma tentativa de homogeneização da língua brasileira, que nada mais é do que lugar de segregação, de valorização de uma suposta língua oficial, em detrimento da heterogeneidade de discursos, das diferentes etnias, expressões culturais e modos de falar/ ser e sentir. 
A pretensão de uma homogeneidade da língua é uma farsa, ideologicamente ainda reforçada. Uma investigação sobre a língua deve ser ampliada para diversas áreas do saber, a fim de que se abram espaços de discussão e reflexão numa perspectiva abrangente. A língua engloba campos insondáveis, expressões, sotaques, costumes rituais, o que inclui uma gama de falantes e de condições de vida, assim como de intercâmbios culturais, relações político-econômicas entre pessoas e países. Língua é polissemia, é diferença e multiplicidade, não se tendo um monopólio linguístico, como nos alerta Rajagopalan (2014b). Compreender a língua é algo estruturalmente interdisciplinar, é multicultural e não restrito a uma categoria intelectual que teria o domínio sobre esse objeto.

Voltamos à ideia de que a leitura do fenômeno linguístico deve estar ancorada na compreensão de que o discurso constitui a vida social e, graças a ela, torna-se possível. É na dialética entre linguagem e existência que se pode pensar possibilidades de intervenção nos rumos da história, nos acontecimentos sociais que afetam os sujeitos e nas suas atuações no mundo. É resistindo à onipotência da suposta racionalidade inconteste, que se pode compreender um pouco melhor a história alheia e a nossa.

Ao narrarmos, escrevermos e mesmo silenciarmos, demarcamos posições no mundo. Nossos discursos e aqueles que analisamos são constructos atravessados por muitos outros discursos, por nossos valores, ideologias, desejos, intenções e interesses. Fabrício (2006, p. 49), ao abordar acerca do perigo de um determinismo explicativo sobre a realidade social, também nos lembra para que tenhamos o cuidado para não cairmos na "tentação de construção de certezas", uma vez que a percepção acerca outro (em termos de classe socioeconômica, status, etnia, gênero, escolaridade etc.) está marcada por nossas ideologias, interesses políticos e nossos valores pessoais.

Assim como um discurso é marcado pela multideterminação e pelo imprevisto, e o sentido só pode ser pensado no uso (práticas sociais), não pode existir uma interpretação direta/ exata entre forma e significado. E sem esquecer, como bem nos mostrou Freud (1986b), que nem sempre (ou com frequência) estamos conscientes do que expressamos por meio da fala, dos atos (que falam), dos sentimentos.

Reconhecer a linguagem em uma perspectiva político-ideológica, como temos acentuado ao logo deste escrito, é um passo importante que nos leva a entender que o sentido que subjaz ao discurso pode não coincidir diretamente com o que ouvimos ou lemos. A linguagem não é transparente, não é auto-evidente. A análise de um enunciado não está pronta, prevista ou encerrada no código linguístico. Ela precisa ultrapassar a noção de literalidade e precisão, considerando que algo emerge do relacionamento entre língua e sociedade. Apenas assim, abrimos espaço para a compreensão de que a significação existe na esfera da existência social, da linguagem em uso, entre sujeitos ativos em seus contextos e com suas histórias singulares. 


\section{CoNSIDERAÇõES FINAIS}

Ao final, apresentamos como resultado central a ideia de que discursos são constructos artificiais (no sentido de oposto ao que é natural ou portador de uma essência) com demarcações políticas e ideológicas específicas e não enunciados desprovidos de interesses ou escolhas. Nesse sentido, eles definem lugares, saberes, mas em um fluxo de permanente mudança, como já assinalado, o que permite rupturas e ressignificações.

A discussão sobre a qual tratamos neste texto, tendo como referência a linguagem, em sua dimensão discursiva, e sendo inseparável do contexto social que a constitui, leva-nos a uma reflexão, e não sem preocupação, com o lugar que é resguardado para o Humano na sociedade contemporânea. Estamos cientes de que a constituição discursiva não surge de uma cadeia de pensamentos aleatórios, desconectados da vida em sociedade, mas das histórias de cada um, bem como das estruturas sociais concretas. A linguagem possibilita os intercâmbios humanos, podendo ser instrumento tanto de transformação social, emancipação humana, quanto de manutenção de ideologias que acirram relações de poder e subjugo. Nesse último caso, perguntamo-nos o que restaria ao sujeito em termos de realização pessoal/profissional, equidade nas relações e de autoria de sua própria história, em um contexto marcado pela desigualdade social, discriminação racial, de gênero e de etnia, assim como por relações de servidão, ainda tão presentes em nossa sociedade.

Acreditamos que a delicadeza de tal temática não nos permitiria esgotar o assunto, mas pensamos ser possível, a partir de uma visão ampla do conceito de Linguagem, levantarmos importantes questões sobre as relações entre construções discursivas (incluímos aqui as apresentadas em movimentos de resistência, aquelas veiculadas pela mídia alternativa, as que emergem nas situações de estudo e de trabalho etc.), posicionamento político e transformação. Essas reflexões acabam por nos posicionar em determinados lugares subjetivos e mesmo políticos, uma vez que põem em evidência concepções de humano, de linguagem e de sociedade. Levam-nos a pensar sobre nossas posições frente ao mundo, sobre nossas escolhas, se libertárias, emancipatórias ou reacionárias e excludentes; se somos movidos pela alteridade ou se optamos pelo aprisionamento do e ao outro.

A partir da experiência de Pós-Graduação, aqui materializada em reflexões sobre o que, simplificadamente, denominaríamos "textos, vidas e lugares", compreendemos que não deve existir análise linguística isenta de posicionamento crítico frente ao fenômeno estudado. Por crítico, referimo-nos à compreensão de linguagem como uma complexa semiose, não separada dos aspectos políticos, sociais, ideológicos e intersubjetivos que a constituem. Tratamos, aqui, da inseparabilidade entre práticas discursivas e vida, entre vozes e desejos, entre silêncios, brados e poderes.

É somente no campo de uma ética que podemos perceber que não há captação objetiva do discurso, bem como das realidades sociais. E também não há neutralidade, posto que nossas 
apreciações são inseparáveis de uma posição de sujeito e de escolhas teóricas que interpretam, de uma forma e não de outra, a realidade social. Consideramos essencial uma reflexão sobre a linguagem em seu caráter criador e organizador de sentidos e atos, na sociedade contemporânea; um espaço que abriga o risco, a diversidade, a contradição e a desigualdade das condições de existência humana.

É exatamente neste universo contraditório, permeado por relações de equidade e opressão, que se torna necessário enxergarmos os que sofrem, os que são subjugados, violentados e vistos como inferiores. Devemos nos posicionar, como salienta Fabrício (2006), como sujeitos (estudiosos da linguagem, cidadãos, pesquisadores em Linguística Aplicada etc.) que precisam assumir um lugar de agentes de possibilidades, nos diversos espaços sociais, fazendo oposição aos discursos hegemônicos que compreendem as condições de vida de um determinado grupo ou "indivíduo" de forma etnocêntrica, preconceituosa e excludente. Desse modo:

Os espaços marginais, bem como o modo de focalizá-los, seriam um lócus de ocorrência do novo, e com eles poderíamos aprender a 'ver com outros olhos'. As opções políticas envolvidas nessa ótica têm implicações para a construção do presente e futuros sociais possíveis, menos aprisionadores e mais comprometidos com a transformação de situações de exclusão social em diversas áreas, causadoras de sofrimento humano. É em razão dessas possibilidades que as escolhas temáticas e teóricas se justificam, e não em razão de uma superioridade epistemológica (FABRÍCIO, 2006, p. 52).

Precisamos estar atentos à subtração de vidas, à negação da condição de sujeitos, ou seja, aos atos de opressão, de segregação, à dinâmica de violência nas relações, vigilantes para entender se um texto (em suas variadas formas), se a concepção de linguagem ali implicada, está entrelaçada à luta contra hegemonias totalitárias, se extirpam a dimensão de humanidade ou se faz referência a interesses democráticos, em prol de uma coletividade.

Fairclough (2008) levanta um debate necessário acerca do conceito de ideologia, em sua relação com o discurso, abordada como determinadas significações sobre o mundo/fenômenos, que contribuem para construção ou reprodução da realidade. Compreende que mesmo reconhecendo-se que ideologias (antidemocráticas, nazifascistas etc.), intrínsecas a determinadas práticas discursivas, possam ser naturalizadas no cotidiano e trazer efeito devastador para a vida de muitos, os sujeitos não podem se fixar nessa ideia. Ao contrário, o autor concebe a luta ideológica como dimensão da prática discursiva, sendo a ideologia propriedade de estruturas (ordens de discurso) e de eventos, o que a põe na esfera da transformação. Por mais que a ideologia esteja na dimensão da estabilidade, ela é parte de uma construção discursiva e, por essa especificidade, pode perder seu significado na realidade, pode deixar de ter uma posição de "verdade". 
Afinal, vivenciamos rupturas e o desconcerto em diferentes ocasiões históricas, como bem enfatiza Fabrício (2006), que expressam as realidades de cada época, mas que parecem ratificar que a transição é regra. E é nesse movimento contínuo, que oscila entre manutenção e corte, que precisamos pensar a vida em sociedade e os discursos, em sua dimensão de ato, de produtores de realidades concretas, que ora permanecem cristalizadas, ora mostram um caráter subversivo, mutante e de contra poder presente nas formações discursivas, que sempre escaparão ao acorrentamento, às hegemonias de classe e as tiranias. E é nessa impossibilidade de aprisionar o dito, em seu significado de ato e de sonho, que sempre haverá abertura de tempo para a criação, para a reinvenção em meio às tortuosidades de um espaço no qual insistimos em preservar o seu caráter humanizador; sua dimensão eminentemente civilizatória e o reconhecimento dos sujeitos como (re) construtores de suas próprias histórias.

\section{REFERÊNCIAS}

BLOMMAERT, Jan. Contexto é/como crítica. In: SIGNORINI, I. (Org.). Situar a lingua[gem]. São Paulo: Parábola, 2008.

BLOMMAERT, Jan. Ideologias linguísticas e poder. In: SILVA, Daniel do Nascimento e; FERREIRA, Dina Maria Martins; ALENCAR, Claudiana Nogueira de. (Org.). Nova pragmática: modos de fazer. São Paulo: Cortez, 2014.

FABRÍCIO, Branca Falabella. Linguística Aplicada como espaço de desaprendizagem. In: Moita Lopes, Luiz Paulo da. (Org.). Por uma Linguística Aplicada Indisciplinar. São Paulo: Parábola, 2006.

FAIRCLOUGH, Norman. Discurso e mudança social. Brasília: Editora Universidade de Brasília, 2008.

FIGUEIREDO, Luis Cláudio Mendonça. Matrizes do pensamento psicológico. Rio de Janeiro: Vozes, 2000.

FOUCAULT, Michel.Microfísica do poder. 18. ed. Rio de Janeiro: Edições Graal, 2003.

FREUD, Sigmund. Conferências Introdutórias sobre Psicanálise. Conferência I. In: Edição Standard Brasileira das Obras Completas de Sigmund Freud.v. 15. Rio de Janeiro: Imago, 1986a [1916].

FREUD, Sigmund. O inconsciente. In: Edição Standard Brasileira das Obras Completas de Sigmund Freud. v. 14. Rio de Janeiro: Imago, 1986b [1915].

JAPIASSU, Hilton.Nascimento e morte das ciências humanas. 2. ed. Rio de Janeiro: F. Alves, 1982.

LEEZENBERG, Michiel. Em torno de uma abordagem prática em pragmática: tragédia grega como conversação impolida. In: SILVA Daniel do Nascimento e; FERREIRA, Dina Maria Martins; ALENCAR, Claudiana Nogueira de. (Org.). Nova pragmática: modos de fazer. São Paulo: Cortez, 2014. 
MUSSALIM, Fernanda. Análise do discurso. In: MUSSALIM, Fernanda; BENTES, Anna Christina. (Org.). Introdução à linguística: domínios e fronteiras. 8. ed. São Paulo: Cortez Editora, 2012.

PINTO, Joana Plaza. Hegemonias, contradições e desafios em discursos sobre língua no Brasil. In: CORREA, Djane Antonucci. (Org.). Política linguística e ensino de língua. São Paulo: Pontes Editores, 2014.

RAJAGOPALAN, Kanavillil. A nova pragmática: faces e feições de um fazer. São Paulo: Parábola, 2010.

RAJAGOPALAN, Kanavillil. Da arrogância cartesiana à "nova pragmática". In: SILVA Daniel do Nascimento e; FERREIRA, Dina Maria Martins; ALENCAR, Claudiana Nogueira de. (Org.). Nova pragmática: modos de fazer. São Paulo: Cortez, $2014 a$.

RAJAGOPALAN, Kanavillil. O professor de língua e a suma importância do seu entrosamento na política linguística de seu país. In: CORREA, Djane Antonucci. (Org.). Política linguística e ensino de língua. São Paulo: Pontes Editores, 2014b.

SILVA, Daniel do Nascimento e; ALENCAR, Claudiana Nogueira de. Violência e significação: uma perspectiva pragmática. In: SILVA, Daniel do Nascimento e; FERREIRA, Dina Maria Martins; ALENCAR, Claudiana Nogueira de. (Org.). Nova pragmática: modos de fazer. São Paulo: Cortez, 2014.

Recebido para publicação em: 14 jun. 2020. Aceito para publicação em: 22 jan. 2021. 